\title{
Massa das sementes de Tecoma stans L. Juss. ex Kunth (Bignoniaceae): efeitos na emergência e desenvolvimento de suas plântulas no sol e na sombra
}

\author{
Fábio Socolowski ${ }^{1,3}$, Daniela Cristine Mascia Vieira ${ }^{2} \&$ Massanori Takaki $^{2}$
}

${ }^{1}$ Departamento de Produção Vegetal, Escola Superior de Agricultura "Luiz de Queiroz" - ESALQ, Universidade de São Paulo - USP, Av. Pádua Dias, 11, CP 9, CEP 13418-900, Piracicaba, SP, Brasil

${ }^{2}$ Departamento de Botânica, Universidade Estadual Paulista “Júlio de Mesquita Filho” - UNESP,

Av. 24 A, 1515, CP 199, CEP 13506-900, Rio Claro, SP, Brasil

${ }^{3}$ Autor para correspondência: Fábio Socolowski, e-mail: fsocolowski@yahoo.com.br

\begin{abstract}
SOCOLOWSKI, F., VIEIRA, D.C.M. \& TAKAKI, M. Seed mass of Tecoma stans L. Juss. ex Kunth (Bignoniaceae): effects on emergence and seedling development under full sun and shade. Biota Neotrop. 11(2): http://www.biotaneotropica.org.br/v11n2/en/abstract?article+bn03411022011
\end{abstract}

\begin{abstract}
The aim of this study was to evaluate the effect of Tecoma stans L. Juss. ex Kunth seeds mass on initial emergence, growth and, seedling development under different light conditions. The seeds were separated in four mass classes and sowed in four replicates of 24 seeds for each class, under full sun and canopy shade. Under sun environment was observed a greater percentage of emergence. Heavy seeds presented the greater percentage of emergence under both environments, but a greater rate was observed under canopy shade. One month after the start of experiments, the seedlings at the shade environment presented $100 \%$ of mortality. The growth and development seedlings under full sun were noticed for five months. In this period, only in the first three months was possible to observe the effects of Tecoma stans seeds mass on capacity of seedlings to acquire dry mass. The seedlings biomass partitions were similar among the tested mass class. The seedlings of smaller mass tended to a high specific leaf area in relation to the seedlings from large seeds, mainly in the first three months, resulting in a great acquisition of dry mass by these seedlings. In the fourth month, the specific leaf area did not present any tendency. Because the biggest seeds to give rise seedlings with best initial development than smallest seeds can be considered as species reproductive strategy. To produce seeds of different sizes also can be considered as way of species to spread in many microhabitats.
\end{abstract}

Keywords: seedling growth, seed mass, seed size, shading, yellow bells.

SOCOLOWSKI, F., VIEIRA, D.C.M. \& TAKAKI, M. Massa das sementes de Tecoma stans L. Juss. ex Kunth (Bignoniaceae): efeitos na emergência e desenvolvimento de suas plântulas no sol e na sombra. Biota Neotrop. 11(2): http://www.biotaneotropica.org.br/v11n2/pt/abstract?article+bn03411022011

Resumo: Este estudo teve como objetivo avaliar o efeito da massa das sementes de Tecoma stans L. Juss. ex Kunth na emergência, no crescimento e no desenvolvimento inicial de suas plântulas sob diferentes condições de luminosidade. As sementes foram separadas em quatro classes de massa e semeadas em quatro réplicas de 24 sementes para cada classe, no sol e na sombra. No ambiente de sol ocorreu a maior porcentagem de emergência. Dentre as classes de massa, sementes maiores apresentaram maior porcentagem de emergência em ambos os ambientes, porém a maior velocidade foi observada na sombra. Após um mês do início do experimento as plântulas da sombra apresentaram $100 \%$ de mortalidade. O crescimento e desenvolvimento das plântulas no sol foram acompanhados mensalmente por um período de cinco meses. Neste período, foi possível observar os efeitos da massa das sementes de Tecoma stans no ganho de massa seca das plântulas nos três primeiros meses; a partir deste, a massa das sementes não teve efeito no ganho de matéria seca pelas plântulas. A partição da biomassa das plântulas não diferiu entre as classes de massa testadas. As plântulas de menor massa apresentaram uma tendência a uma maior área foliar específica em relação às plântulas originárias de sementes mais pesadas, principalmente nos três primeiros meses, resultando em um ganho maior de matéria seca das plântulas de menor classe de massa. Já no quarto mês, a área foliar específica não apresentou qualquer tendência. $\mathrm{O}$ fato de sementes maiores originarem plântulas com melhor desenvolvimento inicial quando comparadas com as sementes menores pode ser considerada como estratégia reprodutiva da espécie, assim como produzir sementes de diversos tamanhos pode ser considerado como uma maneira da espécie dispersar-se e colonizar um maior número de microambientes. Palavras-chave: crescimento de plântula, massa da semente, tamanho da semente, sombreamento, ipê-de-jardim. 


\section{Introdução}

Uma semente é exposta às sucessivas ameaças desde o momento de sua formação e está sujeita ao ataque de predadores ou patógenos enquanto ligada à planta mãe ou mesmo após a dispersão, podendo ser enterrada em locais profundos ou rasos e se germinar, sua plântula estará só em um ambiente hostil ou em competição com outras plantas (Westoby et al. 1992). Nesses casos a massa das sementes apresenta efeito relevante nas respostas à predação, capacidade de dispersão e desempenho das sementes maiores na germinação, sobrevivência e crescimento (Khan 2004).

Segundo Lehtilä \& Ehrlén (2005), a grande parte da variação do tamanho da semente é provavelmente devido à plasticidade fenotípica; assim, a variação do tamanho da semente pode ocorrer entre populações, entre frutos de uma mesma planta ou mesmo dentro de um fruto. Contudo, estes mesmos autores consideraram que a plasticidade fenotípica é adaptativa somente se a variação do tamanho das sementes for correlacionada com sua qualidade, ou seja, o tamanho das sementes apresentando uma relação positiva com o desempenho das plântulas. Zimmerman \& Weis (1983) consideraram a importância do efeito desta variação no tamanho dos frutos na germinação e crescimento das plântulas de Xanthium strumarium L. e observaram fortes correlações positivas entre o tamanho dos frutos e o tamanho das sementes, e entre o tamanho dos frutos e o desenvolvimento inicial das plântulas, correlação esta desaparecendo nas plântulas mais velhas. De acordo com Khan (2004), a massa das sementes tem uma relevância chave no desenvolvimento da fase juvenil do ciclo de vida das plantas, com a disponibilidade de reservas das sementes influenciando o estabelecimento subsequiente das plântulas. Mas, isto não garante necessariamente a sua sobrevivência até a maturidade (Susko \& Lovett-Doust 2000).

A qualidade fisiológica das sementes é caracterizada pela germinabilidade e pelo vigor, que é uma soma de atributos que confere à semente a potencialidade para germinar e resultar rapidamente numa plântula normal sob diversas condições ambientais (Höfs et al. 2004). Em muitas espécies, o potencial fisiológico das sementes pode estar relacionado com o seu tamanho (Almeida et al. 2010).

Tecoma stans L. Juss. Kunth é uma espécie arbustivo-arbórea com sementes anemocóricas (Lorenzi 2000, Lorenzi et al. 2003), provavelmente originária do México (Sandwith \& Hunt 1974), que ocorre naturalmente desde o Sudeste da Flórida e Sul do Texas, nos Estados Unidos, passando pela América Central até o Nordeste da Argentina (Gentry 1992). Atualmente está adaptada e naturalizada em muitas partes da América Tropical e muito utilizada na ornamentação em virtude de suas flores amarelas (Sandwith \& Hunt 1974). No Brasil é utilizada na ornamentação de parques, jardins (Lorenzi 2000, Lorenzi et al. 2003) e também considerada espécie invasora (Ziller 2001) de difícil controle (Passini \& Kranz 1997). Em outras localidades, como no Hawaii, Tecoma stans é invasora bastante comum de áreas perturbadas, causando sérios problemas (Space \& Imada 2004).

O objetivo deste trabalho foi avaliar como a massa das sementes de Tecoma stans influencia a emergência, o crescimento e o desenvolvimento inicial de suas plântulas sob diferentes condições de luminosidade.

\section{Material e Métodos}

As sementes de Tecoma stans L. Juss. ex Kunth foram colhidas de 18 indivíduos localizados no Campus da Unesp de Rio Claro em julho de 2003. Destes mesmos indivíduos também foram colhidos 35 frutos secos, com as valvas ainda fechadas, para a determinação de dez classes de massa segundo Fowler et al. (1998). Para isso, foram contadas e pesadas todas as sementes contidas em cada fruto.
Após a determinação destas classes, sementes colhidas de frutos abertos foram separadas nas diferentes classes de massa, totalizando 3.664 sementes distribuídas nas classes um a nove (Tabela 1). Devido ao fato das sementes das duas primeiras classes apresentarem baixa germinação (Socolowski 2007) e o número insuficiente de sementes para realizar os experimentos com todas as classes, a emergência, o crescimento e o desenvolvimento das plântulas foram avaliados somente nas classes de massa intermediárias (três a seis).

Os experimentos foram conduzidos no Jardim Experimental da UNESP de Rio Claro e iniciados em janeiro de 2004. Foram testados dois ambientes, um a pleno sol e outro na sombra. Foram utilizadas quatro repetições de 24 sementes por classe de massa em cada ambiente testado. As sementes foram semeadas a $1 \mathrm{~cm}$ de profundidade em tubetes de $27 \mathrm{~mm}$ de diâmetro e $127 \mathrm{~mm}$ de comprimento contendo Plantmax ${ }^{\circledR}$ (Eucatex, São Paulo, Brasil) como substrato. A emergência das plântulas foi observada diariamente por um período de 30 dias, sendo considerada como emergentes as plântulas que romperam o substrato e abriram seus cotilédones. A irrigação foi feita nos dias em que não ocorreu precipitação. A porcentagem de emergência, o tempo médio $(\bar{t})$, a velocidade média $(\bar{v})$, a frequiência relativa $(f i)$ e o índice de sincronização de emergência (U) foram calculados de acordo com Labouriau \& Agudo (1987). As equações utilizadas foram (Equações 1, 2, 3 e 4):

$$
\bar{t}=\sum_{i=1}^{k} n_{i} t_{i} / \sum_{i=1}^{k} n_{i}
$$

onde $n i$ : número de sementes que emergiram no tempo $t i$ (não o número acumulado, mas o número referido para a $i$-ésima observação), ti: tempo entre o início do experimento e a $i$-ésima observação, $k$ : último tempo de emergência das sementes;

$$
\bar{v}=1 / \bar{t}
$$

onde $(\overline{\mathrm{t}})$ : tempo médio de emergência;

$$
f_{i}=n_{i} / \sum_{i=1}^{k} n_{i}
$$

onde $n i$ : número de sementes que emergiram no tempo $t i, k$ : último tempo de emergência das sementes;

$$
\mathrm{U}=-\sum_{i=1}^{k} f_{i} \log _{2} f_{i}
$$

onde $f$ : freqüência relativa de emergência, $k$ : último dia de observação.

Tabela 1. Amplitude e número de sementes em cada classe de massa de Tecoma stans.

Table 1. Amplitude and number of seeds in each mass class of Tecoma stans.

\begin{tabular}{ccc}
\hline $\begin{array}{c}\text { Classe de } \\
\text { massa }\end{array}$ & $\begin{array}{c}\text { Amplitude } \\
(\mathbf{m g})\end{array}$ & $\begin{array}{c}\text { Número de } \\
\text { sementes }\end{array}$ \\
\hline 1 & $0,2-1,7$ & 856 \\
2 & $1,8-3,3$ & 649 \\
3 & $3,4-4,9$ & 270 \\
4 & $5,0-6,5$ & 704 \\
5 & $6,6-8,1$ & 656 \\
6 & $8,2-9,7$ & 472 \\
7 & $9,8-11,3$ & 30 \\
8 & $11,4-12,9$ & 24 \\
9 & $13,0-14,5$ & 3 \\
10 & $14,6-16,1$ & 0 \\
\hline
\end{tabular}


A cada 30 dias foram sorteados dez indivíduos de cada classe para as análises, durante um período de cinco meses. Foram medidas a área foliar, massa seca da raiz, do caule, das folhas e dos cotilédones.

A área foliar foi determinada através da fotocópia das folhas de cada indivíduo, as quais foram posteriormente escaneadas e calculado o número de pontos pretos, com o programa PCXAREA. As massas secas foram obtidas após a secagem do material em estufa a $70{ }^{\circ} \mathrm{C}$ por 48 horas. A partição da biomassa foi determinada pela proporção de matéria seca das diferentes partes da planta em relação à matéria seca total da planta, bem como a área foliar específica (AEF): $\mathrm{AEF}=\mathrm{AF} / \mathrm{MSF}$, onde $A F$ : área foliar, $M S F$ : massa seca das folhas (Hunt 1982).

Após a segunda leitura, todos os indivíduos foram transplantados para sacos plásticos $(20 \times 40 \mathrm{~cm})$, contendo uma mistura de terra de barranco e húmus de minhoca. Na terceira leitura os sacos foram redistribuídos no canteiro para minimizar a competição por luz entre eles.

Para a comparação entre as porcentagens médias, transformadas em arcoseno da raiz quadrada, velocidades médias e índices de sincronização obtidos nos experimentos de emergência, nos ambientes de sol e sombra, nas diferentes classes de massa, foi utilizada uma análise de variância de dois fatores (ANOVA-two way) (Zar 1999).

O ganho de massa seca total das plântulas (g) em cada mês foi comparado através de uma análise de variância (ANOVA) seguida do teste de Tukey $\alpha=5 \%$ (Zar 1999). Com a relação da massa seca das plântulas e a área foliar específica, determinadas por funções lineares e não lineares (Batschelet 1978), com medidas das 40 plântulas sorteadas.

\section{Resultados e Discussão}

A porcentagem de emergência das plântulas de Tecoma stans L. Juss. ex Kunth foi maior no ambiente de sol do que na sombra $(P=0,000)$. A massa das sementes também influenciou a porcentagem final de emergência $(P=0,000)$, com as sementes de maior massa dando origem a um maior número de plântulas (Figura 1). Lehtilä \& Ehrlén (2005) também observaram uma associação positiva entre o tamanho das sementes e o número de plântulas em Primula veris L. (Primulaceae). Em Artocarpus heterophyllus L. (Moraceae), a maior germinação foi atribuída à grande reserva de nutrientes encontradas nas sementes maiores (Khan 2004).

A interação entre as classes de massa e os ambientes não foi significativa $(P=0,907)$, demonstrando que, independente do ambiente, quanto maior a massa da semente maior foi a porcentagem de emergência (Figura 1). Entretanto, as velocidades de emergência das plântulas não diferiram entre as classes de massa $(P=0,208)$. Diferentemente, os ambientes afetaram a velocidade $(P=0,000)$, com as sementes semeadas na sombra emergindo suas plântulas mais rapidamente. A interação não foi observada entre as classes de massa das sementes e os ambientes de sol e sombra $(P=0,940)$ como pode se observado na Figura 2. Além disso, podemos observar que a emergência das plântulas tende a uma velocidade média maior para as sementes mais leves, as quais apresentaram uma maior amplitude de variação na porcentagem e velocidade de emergência de suas plântulas, o que pode refletir uma menor qualidade fisiológica das sementes nestas classes de massa (Figura 2).

Susko \& Lovett-Doust (2000) observaram que sementes menores de Alliaria petiolata (M. Bieb.) Cavara e Grande (Brassicaceae) germinaram mais rapidamente do que sementes maiores. Segundo Zimmerman \& Weis (1983), plântulas que emergem mais rápido capturam uma maior quantidade de recursos disponíveis quando comparadas com aquelas que germinam mais tarde, as quais podem apresentar um aumento na mortalidade ou redução no seu crescimento.
Segundo Stamp (1990), sementes pequenas germinam mais rapidamente do que sementes grandes, devido ao maior acesso à água em função da alta razão superfície:volume.

Em Artocarpus heterophyllus, espécie arbórea nativa da Índia, a porcentagem de germinação foi positivamente correlacionada com a massa de suas sementes e a velocidade de germinação aumentou significativamente com a massa e o nível de luminosidade (Khan 2004). Contrariamente, para Dipterocarpus macrocarpus Vesque, outra espécie nativa da Índia, o tempo de germinação diminuiu com o aumento da massa das sementes (Shankar 2006).

A sincronização da emergência não foi alterada pelo ambiente $(P=0,587)$ nem mesmo pela massa das sementes $(P=0,687)$ e a interação entre os ambientes e as classes de massa também não foi significativa $(P=0,814)$, demonstrando que, independente do ambiente ou da massa das sementes, a emergência ocorre de maneira igualmente sincronizada, embora com porcentagens e velocidades diferentes. Já a freqüência relativa da emergência mostra que o ambiente influencia o comportamento das sementes. O pico da emergência das plântulas das sementes semeadas na sombra ocorreu no sétimo dia, independente da classe de massa das sementes. As sementes semeadas e mantidas no sol da classe 3 apresentaram um primeiro pico de emergência no sétimo e outro pico no décimo terceiro

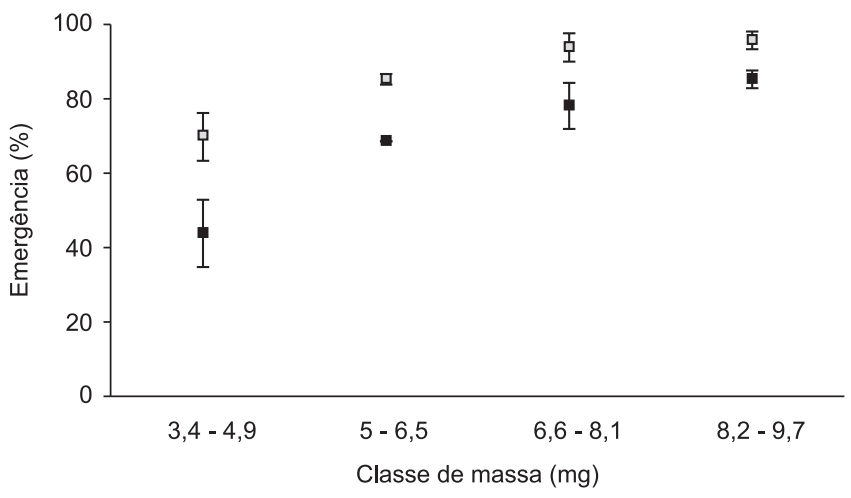

Figura 1. Porcentagem média de emergência de plântulas para cada classe de massa das sementes de Tecoma stans semeadas no sol (ם) e na sombra ( $\square$ ). Barras verticais indicam o erro padrão da média.

Figure 1. Mean percentage of seedling emergence for each mass class of Tecoma stans seeds sowed under sun (ם) and shade (ם). Vertical bars indicate the standard error.

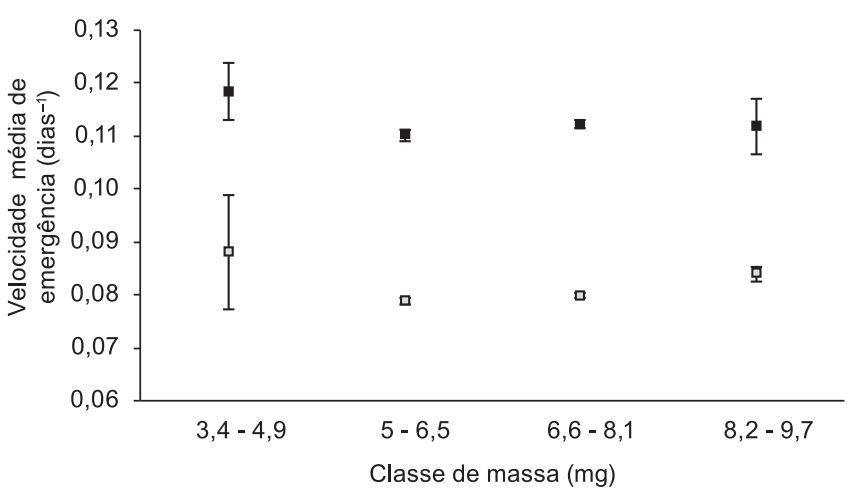

Figura 2. Velocidade média de emergência de plântulas para cada classe de massa das sementes de Tecoma stans semeadas no sol (ㅁ) e na sombra ( $\square$ ). Barras verticais indicam o erro padrão da média.

Figure 2. Mean rate of seedling emergence for each mass class of Tecoma stans

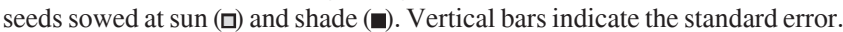


dia enquanto que as sementes das demais classes apresentaram um único pico, por volta do $11^{\circ}$ e $12^{\circ}$ dia (Figura 3). Também podemos notar que a emergência das plântulas começou no sexto dia em quase todos os tratamentos, com exceção das classes 5 e 6 a pleno sol, muito provavelmente devido à lenta embebição das sementes maiores neste ambiente, além disso, todas as classes de massa apresentaram uma distribuição polimodal da freqüência de emergência.

A pleno sol, apenas dois indivíduos da classe 5 morreram no $18^{\circ}$ dia. No entanto, a sobrevivência dos indivíduos no ambiente de sombra começou a diminuir a partir do $14^{\circ}$ dia na classe 3 , a partir
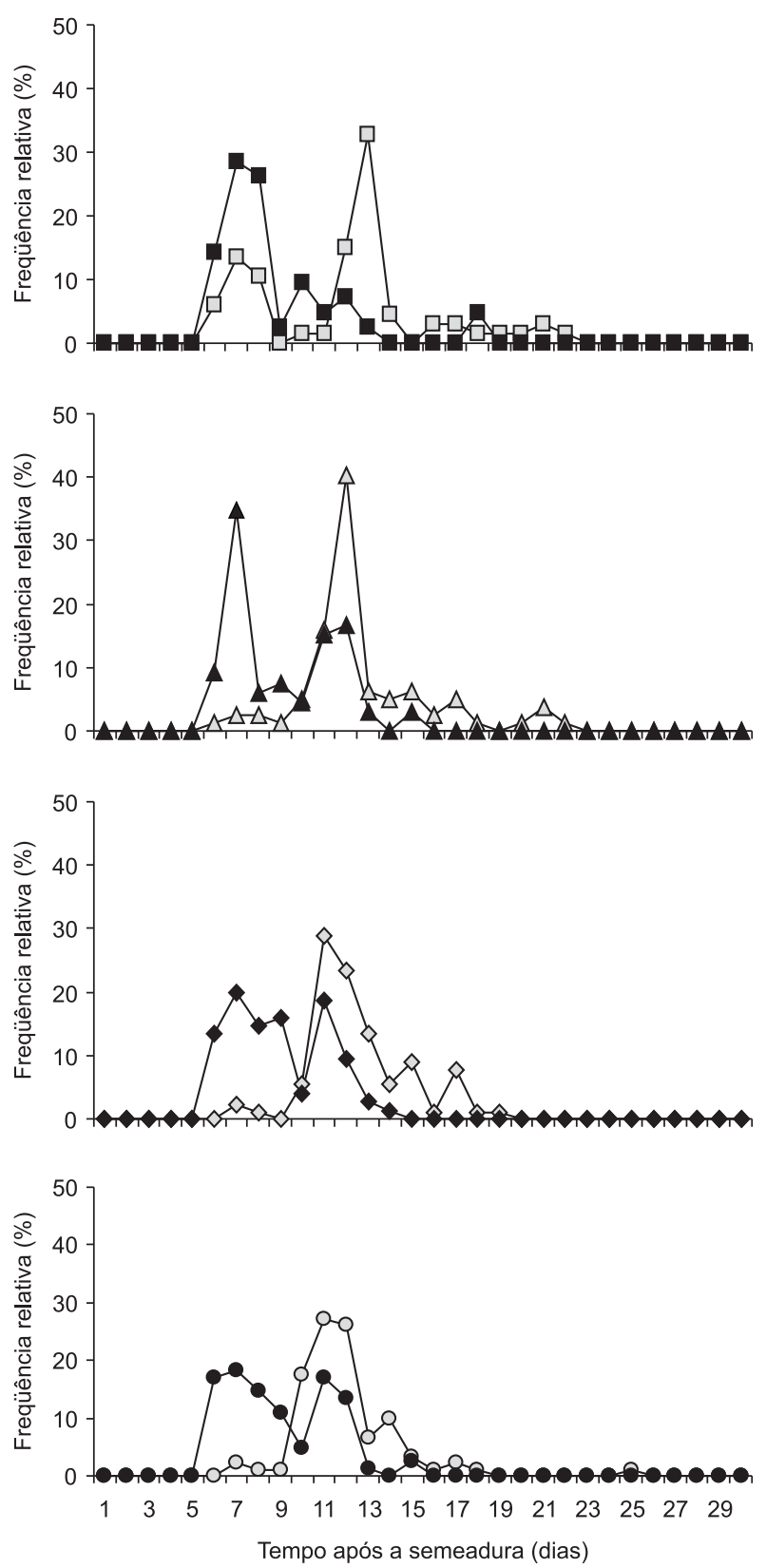

Figura 3. Frequiência relativa de emergência das plântulas de Tecoma stans nas classes de massa. Sementes da classe 3 semeadas no sol (ㅁ) e na sombra $(\square)$; sementes da classe 4 semeadas no sol $(\Delta)$ e na sombra $(\boldsymbol{\Delta})$; sementes da classe 5 semeadas no sol $(\diamond)$ e na sombra $(\diamond)$; sementes da classe 6 semeadas no sol (o) e na sombra $(\bullet)$.

Figure 3. Relative frequency of seedling emergence of Tecoma stans in the mass classes. Seeds of class 3 sowed at sun ( $\square$ ) and shade ( $\square$ ); seeds of class 4 sowed at sun $(\Delta)$ and shade $(\mathbf{\Delta})$; seeds of class 5 sowed at sun $(\diamond)$ and shade $(\bullet)$; seeds of class 6 sowed at sun (o) and shade $(\bullet)$. do $16^{\circ}$ nas classes 4 e 5 e somente no $18^{\circ}$ dia na classe 6 , restando ao $30^{\circ}$ dia somente um indivíduo da classe 6 (Figura 4). De acordo com Khan (2004), plântulas de Artocarpus heterophyllus que emergem de sementes grandes sobrevivem melhor do que aquelas provenientes de sementes pequenas, sendo esta sobrevivência também afetada pelas condições de luminosidade a que foram submetidas, crescendo mais rapidamente sob condições de luminosidade alta e intermediária do que sob luminosidade baixa.

Estes resultados demonstraram que a massa das sementes influencia somente a porcentagem final de emergência e que Tecoma stans recruta uma maior quantidade de plântulas a pleno sol, porém a velocidade de emergência é maior na sombra, provavelmente devido às condições de temperaturas mais amenas e, conseqüentemente, maior disponibilidade hídrica observada neste ambiente. Contudo, as plântulas na sombra não suportaram as condições ambientais geradas pelo sombreamento e morreram. Estas plântulas apresentavam uma coloração verde-amarelada e com o passar dos dias surgiram manchas escuras nos cotilédones e finalmente murcharam ou desapareceram.

$\mathrm{O}$ fato de Tecoma stans não recrutar em ambiente sombreado confirma o seu comportamento invasor em áreas abertas. A intolerância ao sombreamento é observada na maioria das espécies exóticas invasoras (Vieira 2009), por serem heliófitas e se estabelecem em ambientes bastante iluminados (Dislich et al. 2002).

A biomassa inicial de plântulas de Psychotria spp. (Rubiaceae) foi positivamente correlacionada com a massa das sementes, em todas as espécies estudadas, porém a sobrevivência das plântulas foi correlacionada com a massa das sementes em seis das sete espécies, em pelo menos um habitat, do total de três associações entre clareira e floresta madura estudadas (Paz \& Martínez-Ramos 2003).

Fenner (1987) considerou que determinar a causa da morte das plântulas representa um problema, já que muitas plântulas podem simplesmente desaparecer em um intervalo de 24 horas de observação e mesmo que não desapareça, é muito difícil determinar a causa desta mortalidade. Este mesmo autor chama a atenção para alguns motivos que podem levar as plântulas à morte, como a deficiência de água, a predação das raízes, as doenças ou qualquer defeito genético. De acordo com Augspurger (1984), que estudou o crescimento e sobrevivência de várias espécies arbóreas na ilha de Barro Colorado, Panamá, a maior causa da mortalidade das plântulas encontradas na sombra ocorre devido às doenças provocadas por fungos patogênicos

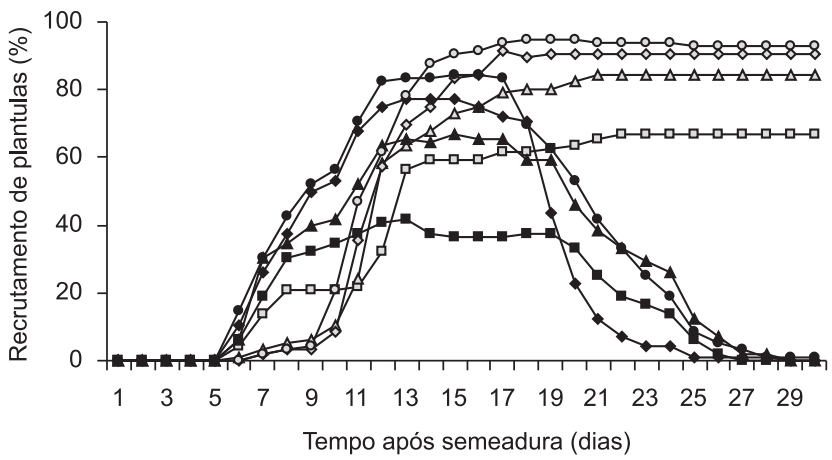

Figura 4. Recrutamento das plântulas de Tecoma stans nas diferentes classes de massa após um mês da semeadura. Sementes da classe 3 semeadas no sol (ㅁ) e na sombra $(\square)$; sementes da classe 4 semeadas no sol $(\Delta)$ e na sombra $(\mathbf{A})$; sementes da classe 5 semeadas no sol $(\diamond)$ e na sombra $(\boldsymbol{\nabla})$; sementes da classe 6 semeadas no sol (o) e na sombra (•).

Figure 4. Recruitment of seedlings of Tecoma stans in the different mass classes one month after sowing. Seeds of class 3 sowed at sun (ㅁ) and shade $(\boldsymbol{\square})$; seeds of class 4 sowed at sun $(\Delta)$ and shade $(\mathbf{\Delta})$; seeds of class 5 sowed at sun $(\diamond)$ and shade $(\diamond)$; seeds of class 6 sowed at sun (o) and shade $(\bullet)$. 
e que as espécies tolerantes à sombra, no ambiente de sombra, são menos suscetíveis às doenças do que as espécies menos tolerantes.

Figueroa \& Vázquez-Yanes (2002) sugeriram que a ausência de recrutamento de plântulas de Heliocarpus appendiculatus (Tiliaceae), espécie pioneira nativa do México, sob o dossel da floresta não se deve a uma germinação dependente da luz, e sim de uma redução na germinação sob a serrapilheira ou, provavelmente, a alguma deficiência das plântulas para se estabelecerem neste ambiente. De acordo com Paz \& Martínez-Ramos (2003), sementes maiores têm uma maior emergência através da serrapilheira.

Durante os cinco meses de acompanhamento do crescimento das plântulas a pleno sol pôde-se observar que a massa das sementes correlacionou positivamente com o ganho de matéria seca das plântulas, porém somente nos três primeiros meses (Figura 5). As plântulas provenientes da maior classe de massa das sementes apresentaram massa seca maior, contudo a partir do quarto mês não existiu mais diferença entre a matéria seca das plântulas resultantes de diferentes classes de sementes (Figura 5). Isso indica que mesmo plântulas originárias de sementes pequenas, durante o seu desenvolvimento apresentam alguma característica fisiológica que possibilita um maior ganho de massa e maior desenvolvimento. Resultado semelhante também foi observado por Höfs et al. (2004), em Oryza sativa L., onde sementes de menor qualidade fisiológica apresentaram maiores taxas de crescimento relativo, reduzindo assim, as diferenças iniciais de biomassa seca. Igualmente, Pastinaca sativa L. manteve a biomassa da parte aérea das plântulas aos 10, 20 e 30 dias após a emergência positivamente relacionada com a biomassa das sementes, mas com 40 dias esta relação deixou de ser significativa (Hendrix et al. 1991). Do mesmo modo, Paz \& Martínez-Ramos (2003) observaram que para espécies de Psychotria, a biomassa inicial das plântulas foi positivamente correlacionada com a massa das sementes, tanto em clareiras como sob o dossel da floresta, contudo após um ano de crescimento, cinco das sete espécies estudadas ainda apresentavam a mesma correlação em pelo menos um dos ambientes estudados.
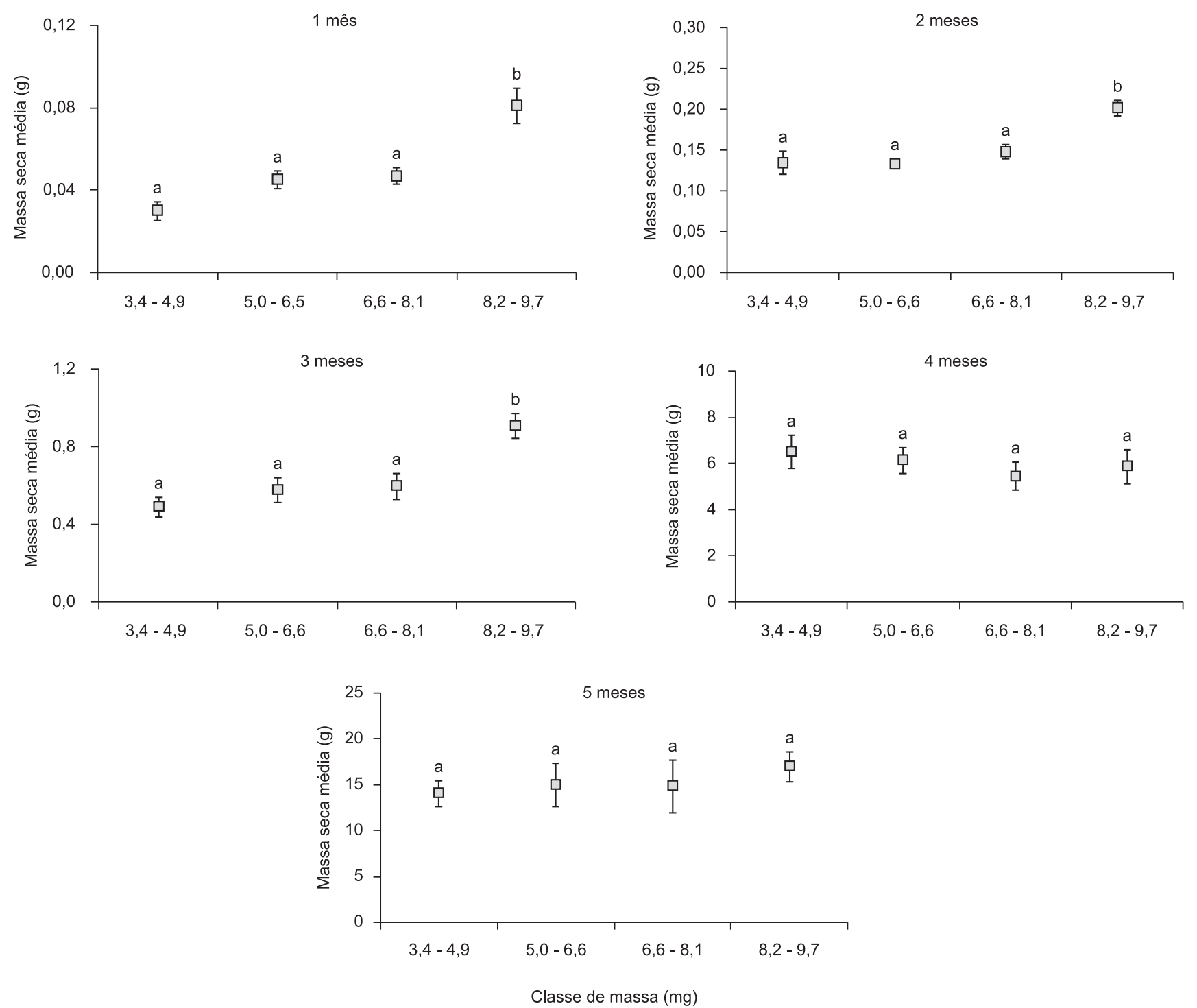

Figura 5. Massa seca média acumulada pelas plântulas de Tecoma stans, provenientes de sementes de diferentes classes de massa, ao longo dos meses. Barras verticais indicam o erro padrão. Letras iguais indicam que não há diferença significativa entre as médias pelo teste de Tukey $\alpha=0,05$, em cada mês.

Figure 5. Mean accumulated dry mass by seedlings of Tecoma stans, proceeding from different mass classes of seeds, along of months. Vertical bars indicate the standard error. Equal letters indicate that there is no significant difference among the means by Tukey test $\alpha=0.05$, in each month. 
A partição da biomassa ocorreu de modo semelhante durante os cinco meses de acompanhamento, para todas as classes de massa, com um maior incremento na parte aérea do que nas raízes. No primeiro mês as plântulas apresentaram, em média, um maior incremento na produção de folhas $(40,9 \%$ da biomassa), seguido pela produção de raízes $(29,5 \%)$ e por último nos caules $(10,2 \%)$, demonstrando a importância dos cotilédones $(19,4 \%)$ para as plântulas nessa fase do desenvolvimento.

No segundo mês, após o transplante, as plântulas apresentaram um incremento médio semelhante na produção de folhas $(41,7 \%)$ e raízes $(39,5 \%)$, sendo estes os mais representativos na partição da biomassa, com os caules $(15 \%)$ representando ainda uma pequena fração da massa total das plântulas, seguidos pelos cotilédones $(3,8 \%)$, já menos representativos. Também pode-se observar que, independente da classe de massa, alguns indivíduos já se apresentavam sem os cotilédones.

No terceiro mês de desenvolvimento, observou-se que as plântulas apresentaram um grande incremento médio na produção de folhas $(64,9 \%)$, seguido, na maioria dos casos, pelo incremento em raízes $(19,6 \%)$ e por último nos caules $(15,4 \%)$, além disso, verificou-se que apenas três indivíduos ainda possuíam cotilédones $(0,01 \%)$, sendo um deles pertencente à classe 4 e os outros à classe 6 .

Já no quarto mês, observou-se que o incremento médio na produção de folhas $(59,9 \%)$ permaneceu maior, porém houve uma inversão na partição da biomassa entre raízes $(16,4 \%)$ e caules $(23,8 \%)$, com estes, de modo geral, assumindo uma maior importância na biomassa total das plântulas. No quinto mês, a partição da biomassa ocorreu de modo semelhante ao observado no mês anterior, com um maior investimento médio em folhas $(53,9 \%)$, seguido de caules $(24,7 \%)$ e raízes $(21,5 \%)$, contudo nesses dois últimos meses, as plântulas possivelmente tiveram o desenvolvimento de suas raízes prejudicado pelas condições experimentais. Este grande incremento em biomassa nas raízes, observado no segundo mês de desenvolvimento de Tecoma stans, indica que, nestas condições experimentais, a planta investe primeiramente na absorção de água e nutrientes e em sustentação, criando condições para o desenvolvimento da parte aérea.

Contrariamente, Ramos et al. (2004) observaram que em Amburana cearensis (Allemao) A. C. Smith, espécie de ampla distribuição no Brasil, que ocorre nas florestas estacionais e nos ecótonos floresta/cerrado e floresta, a maior parte da matéria seca foi alocada no sistema radicular, independente da condição de luminosidade e um maior acúmulo de matéria seca com a diminuição do sombreamento. Por outro lado, plântulas de Croton urucurana Baill quando submetidas a diferentes condições de luminosidade, alteraram a partição da biomassa somente quando expostas a $70 \%$ de sombreamento, acumulando mais matéria seca nas folhas e caule do que nas raízes, quando comparado com aquelas mantidas a pleno sol (Alvarenga et al. 2003).

Parker et al. (2004), estudando o efeito da massa das sementes de Pinus strobus L. na partição da biomassa de suas plântulas, observaram uma alteração da alocação dos recursos com a idade das plântulas. Com oito semanas, as plântulas investiram mais no desenvolvimento de folhas e caules em detrimento das raízes, enquanto que com 14 semanas foi possível observar uma inversão deste investimento. Por outro lado, Hendrix et al. (1991) observaram que em sementes de Pastinaca sativa com diferentes massas, a alocação da biomassa nas plântulas, entre raízes e parte aérea, mudou substancialmente ao longo do tempo, com uma pequena variação nesta razão aos 10 e 20 dias após a emergência, mas aos 30 e 40 dias as plântulas provenientes de sementes maiores continham mais biomassa de raiz. Estes mesmos autores consideraram que a partir deste momento, as plântulas originadas de sementes maiores teriam uma vantagem na absorção de água sobre aquelas vindas de sementes menores.

O maior ganho de massa observada nas plântulas das classes inferiores pode estar relacionado com o fato de esses indivíduos apresentarem no primeiro mês uma área foliar específica maior que a observada na maior classe. Esta relação pode ser representada por uma função potência negativa (Figura 6), demonstrando que os indivíduos destas classes de massa apresentaram folhas mais finas e, conseqüentemente, um aparelho fotossintético mais eficiente. Contudo, quando se acrescentam os dados de área e massa seca dos cotilédones no cálculo da área foliar específica, observamos que a relação torna-se linear e negativa $\left(\mathrm{r}^{2}=0,38 ; P=0,000\right)$, mostrando o efeito negativo dos cotilédones para esta relação. Nessa fase do desenvolvimento das plântulas, os cotilédones apresentaram um considerável efeito na área foliar específica, já que a relação observada entre a área cotiledonar específica e a massa seca das plântulas foi linearmente negativa, com baixo coeficiente de determinação $\left(\mathrm{r}^{2}=0,13 ; P=0,027\right)$.

Estes resultados indicam que os cotilédones de Tecoma stans devem funcionar mais como tecidos de reserva do que tecidos fotossintetizantes. Em estudo de Ressel et al. (2004), que avaliaram a morfologia de plântulas de 122 espécies quanto às características cotiledonares e de comprimento do hipocótilo, as plântulas de Bignoniaceae foram identificadas como fanero-epígeoarmazenadoras. Assim, na sombra, uma vez esgotados os recursos presentes nos cotilédones, a alta mortalidade das plântulas pode ser explicada pela baixa capacidade destes em realizar fotossíntese e garantir o desenvolvimento inicial das plântulas. Nesta fase autotrófica, a manutenção de um ganho líquido positivo de carbono será pré-requisito para a sobrevivência da planta (Kitajima 1996).

No segundo mês de desenvolvimento, após o transplante, a área foliar específica apresentou relação linear e negativa com a massa seca das plântulas $\left(\mathrm{r}^{2}=0,16 ; P=0,010\right)$, no terceiro mês a mesma relação também ocorreu de modo significativo, mas novamente com baixo valor do coeficiente de determinação $\left(\mathrm{r}^{2}=0,13 ; P=0,022\right)$, já no quarto mês não foi observada nenhuma relação entre a área foliar específica e o peso seco das plântulas $\left(\mathrm{r}^{2}=0,06 ; P=0,128\right)$ e por fim, no quinto mês a relação volta a ser significativa, linear e negativa, mas outra vez se mostrou com baixo coeficiente de determinação $\left(\mathrm{r}^{2}=0,14 ; P=0,017\right)$. Aparentemente, a maior eficiência fotossintética das plântulas resultantes de sementes menores no primeiro mês de desenvolvimento, resultou em um desenvolvimento

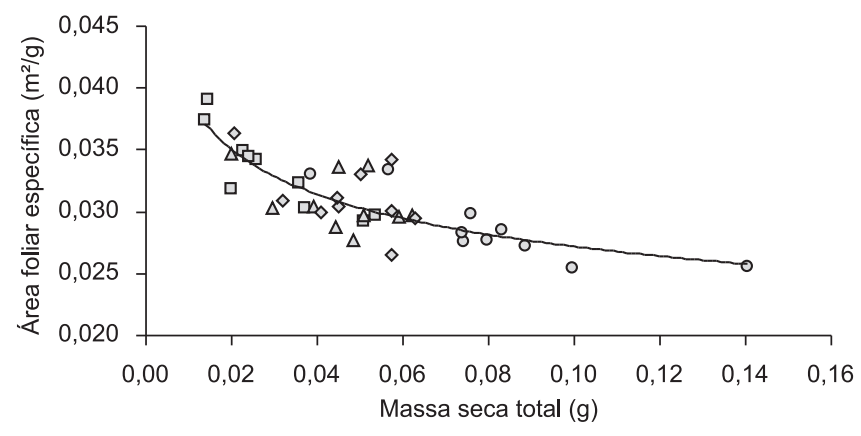

Figura 6. Relação potência entre a massa seca total e a área foliar específica no primeiro mês $\left(\mathrm{n}=40 ; \mathrm{r}^{2}=0,67 ; P=0,05 ; \mathrm{y}=\mathrm{ax}\right.$; onde $\mathrm{a}=0,018950 \mathrm{e}$ $\mathrm{b}=-0,15740)$. Contribuição de cada classe de massa de semente para a relação. (ㅁ) classe 3, $(\Delta)$ classe $4,(\diamond)$ classe 5 e (o) classe 6.

Figure 6. Power relation between the total dry mass and the specific leaf area in the first month $\left(\mathrm{n}=40 ; \mathrm{r}^{2}=0.67 ; P=0.05 ; \mathrm{y}=\mathrm{ax}^{\mathrm{b}}\right.$; where $\mathrm{a}=0.018950$ and $b=-0.15740$ ). Contribution of each mass class of seed to the relation. (ㅁ) class $3,(\Delta)$ class $4,(\diamond)$ class 5 and (o) class 6. 
semelhante ao apresentado pelas plântulas provenientes de sementes de maior classe de massa. Em consequiência de um aumento da capacidade fotossintética, o alto valor da área foliar específica foi positivamente correlacionado a uma elevada taxa de crescimento relativo, como apresentado por Wright \& Westoby (2001) em estudo com 250 espécies e por Wright et al. (2002) para 75 espécies do leste australiano.

A relação entre distribuição espacial e área foliar específica foi investigada em seis espécies arbustivas, que ocorrem na floresta de coníferas na costa oeste do Canadá, e foi negativamente relacionada com a luz, geralmente aumentando do centro das áreas pantanosas em direção ao interior da floresta (Burns 2004). Isso indica que plantas de uma mesma espécie possuem um padrão de variação da área foliar específica em resposta às condições ambientais. Assim, os possíveis efeitos da área foliar específica, observados no ganho de matéria seca nas plântulas de Tecoma stans, podem ocorrer de modo diferenciado se as plântulas forem submetidas a diferentes condições de luz, como apresentado por Burns (2004), em espécies de Ericaceae, ou de disponibilidade hídrica, como demonstrado por Khurana \& Singh (2000) para Albizia procera Benth.

Uma das prováveis explicações para a variação da massa das sementes é a tentativa das espécies para o estabelecimento de suas plântulas em um mosaico de microambientes com diferentes condições físicas e bióticas, ampliando deste modo, o nicho de regeneração (McGinley et al. 1987). Nas condições experimentais testadas, a massa das sementes de Tecoma stans não teve influência na sobrevivência das plântulas na sombra, pois independente do tamanho das sementes não houve sobrevivência neste ambiente. A pleno sol, as sementes menores deram origem à plântulas mais agressivas do que aquelas vindas de sementes maiores, resultando após um período de quatro meses em plântulas de mesma massa, independente das massas das sementes que as originaram. Outra possível explicação para o melhor desempenho das plântulas de Tecoma stans provenientes de sementes pequenas é que, como sugerido por Hendrix et al. (1991), em Pastinaca sativa, estas possuem maior resistência à seca devido a menor perda de água pela transpiração.

Contudo, o tamanho das sementes de Tecoma stans apresentou efeitos importantes na emergência e desenvolvimento inicial de suas plântulas, provavelmente devido a maior disponibilidade de recursos, que propiciou uma maior porcentagem de emergência das plântulas provenientes de sementes maiores e, consequientemente, plântulas com maior massa seca, portanto mais vigorosas, principalmente nos três primeiros meses. No entanto, plântulas originadas de sementes menores apresentaram características que possibilitam uma assimilação mais eficiente da luz solar, o que fez com que elas crescessem mais rapidamente. Os dados apresentados neste trabalho, adicionados às informações aqui discutidas, reforçam a idéia de que os inúmeros ambientes e microambientes observados na natureza devem influenciar a expressão dos efeitos da massa das sementes na emergência e recrutamento das plântulas.

\section{Conclusões}

Em Tecoma stans, as diferenças observadas na emergência das plântulas estão relacionadas à massa das sementes e a sobrevivência das plântulas está relacionada à presença da luz. O crescimento inicial das plântulas depende da massa das sementes. Deste modo, sementes maiores originam plântulas mais vigorosas em seu desenvolvimento inicial quando comparadas com as sementes menores e estas características podem ser consideradas como uma estratégia reprodutiva da espécie. Além disso, produzir sementes de diversos tamanhos pode ser considerado como uma maneira da espécie dispersar-se e colonizar um maior número de microambientes.

\section{Agradecimentos}

F. Socolowski agradece ao CNPq pela bolsa de estudos. Ao CNPq, FAPESP e FUNDUNESP pelo apoio financeiro.

\section{Referências Bibliográficas}

Almeida, M.S., MELO, B., Silva, C.A., SANTANA, D.G. \& SILVA, C.J. 2010. Massa de sementes e profundidades de semeadura no desenvolvimento de mudas de tamarindeiro. Rev. Bras. Frutic. 32:555-560.

ALVARENGA, A.A.,CASTRO,E.M.,LIMAJUNIOR,E.C.\&MAGALHÃES, M.M. 2003. Effects of different light levels on the initial growth and photosynthesis of Croton urucurana Baill. in southeastern Brazil. Rev. Árvore 27:53-57. http://dx.doi.org/10.1590/S0100-67622003000100007

AUGSPURGER, C.K. 1984. Light requirements of neotropical tree seedlings: a comparative study of growth and survival. J. Ecol. 72:777-795. http:// dx.doi.org/10.2307/2259531

BATSCHELET, E. 1978. Introdução à matemática para biocientistas. Interciência, Rio de Janeiro.

BURNS, K.C. 2004. Patterns in specific leaf area and the structure of a temperate heath community. Divers Distrib. 10:105-112. http://dx.doi. org/10.1111/j.1366-9516.2004.00058.x

DISLICH, R., KISSER, N. \& PIVELLO, V.R. 2002. A invasão de um fragmento florestal em São Paulo (SP) pela palmeira australiana Archontophoenix cunninghamiana $\mathrm{H}$. Wendl. \& Drude. Rev. Bras. Bot. 25:55-64.

FENNER, M. 1987. Seedlings. New Phytol. 106:35-47. http://dx.doi. org/10.1111/j.1469-8137.1987.tb04681.x

FIGUEROA, J.A. \& VÁZQUEZ-YANES, C. 2002. Efecto de la calidad de la luz sobre la germinación de semillas en el árbol pionero tropical Heliocarpus appendiculatus (Tiliaceae). Rev. Biol. Trop. 50:31-36.

FOWLER, J., COHEN, L. \& JARVIS, P. 1998. Practical statistics for field biology. Jonh Wiley \& Sons Ltda, Chichester, 254p.

GENTRY, A.H. 1992. Bignoniaceae. New York. Flora Neotropica, pt. 2.

HENDRIX, S.D., NIELSEN, E., NIELSEN, T. \& SCHUTT, M. 1991. Are seedlings from small seeds always inferior to seedling from large seeds? Effects of seed biomass on seedling growth in Pastinaca sativa $\mathrm{L}$. New Phytol. 119:299-305. http://dx.doi.org/10.1111/j.1469-8137.1991. tb01034.x

HÖFS, A., SCHUCH, L.O.B., PESKE, S.T. \& BARROS, A.C.S.A. 2004. Emergência e crescimento de plântulas de arroz em resposta à qualidade fisiológica de sementes. Rev. Bras. Sementes 26:92-97.

HUNT, R. 1982. The functional approach to plant growth analysis. Edward Arnold (Publishers) Limited, London, 246p.

KHAN, M.L. 2004. Effects of seed mass on seedling success in Artocarpus heterophyllus L., a tropical tree species of north-east India. Acta Oecol. 25:103-110. http://dx.doi.org/10.1016/j.actao.2003.11.007

KHURANA, E. \& SINGH, J.S. 2000. Influence of seed size on seedling growth of Albizia procera under different soil water levels. Ann. Bot. 86:1185-1192. http://dx.doi.org/10.1006/anbo.2000.1288

KITAJIMA, K. 1996. Ecophysiology of tropical tree seedlings. In Tropical forest plant ecophysiology (S.S. Mulkey, R.L. Chazdon \& A.P. Smith, eds). Chapman \& Hall, New York, p.559-596.

LABOURIAU, L.G. \& AGUDO, M. 1987. On the physiology of seed germination in Sativa hispania L. I Temperature Effects. An. Acad. Bras. Ciênc. 59:37-56.

LEHTILÄ, K. \& EHRLÉN, J. 2005. Seed size as an indicator of seed quality: a case study of Primula veris. Acta Oecol. 28:207-212. http://dx.doi. org/10.1016/j.actao.2005.04.004

LORENZI, H. 2000. Plantas daninhas do Brasil: terrestres, aquáticas, parasitas e tóxicas. Plantarum, Nova Odessa, 608p.

LORENZI, H., SOUZA, H.M., TORRES, M.A.V. \& BACHER, L.B. 2003. Árvores exóticas no Brasil: madeireiras, ornamentais e aromáticas. Plantarum, Nova Odessa, 368p. 
McGINLEY, M.A., TEMME, D.H. \& GEBER, M.A. 1987. Parental investment in offspring variable environments: theoretical and empirical considerations. Am. Nat. 130:370-398. http://dx.doi.org/10.1086/284716

PARKER, W.C., NOLAND, T.L. \& MORNEAULT, A.E. 2004. Effects of seed mass on early seedling growth of five eastern white pine (Pinus strobus L.) families under contrasting light environments. Canadian. J. Bot. 82:1645-1655. http://dx.doi.org/10.1139/b04-129

PASSINI, T. \& KRANZ, W. 1997. Eficácia de herbicidas no controle de amarelinho (Tecoma stans) em pastagem. Planta Daninha. 15:190-197. http://dx.doi.org/10.1590/S0100-83581997000200012

PAZ, H. \& MARTÍNEZ-RAMOS, M. 2003. Seed mass and seedling performance within eight species of Psychotria (Rubiaceae). Ecology. 84:439-450. http://dx.doi.org/10.1890/0012-9658(2003)084[0439:SM ASPW]2.0.CO;2

RAMOS, K.M.O., FELFINI, J.M., FAGG, C.W., SILVA, J.C.S \& FRANCO, A.C. 2004. Desenvolvimento inicial e repartição de biomassa de Amburana cearensis (Alemão) A.C. Smith, em diferentes condições de sombreamento. Acta. Bot. Bras. 18:351-358. http://dx.doi.org/10.1590/ S0102-33062004000200014

RESSEL, K., GUILHERME, F.A.G., SCHIAVINI, I. \& OLIVEIRA, P.E. 2004. Ecologia morfofuncional de plântulas de espécies arbóreas da Estação Ecológica do Panga, Uberlândia, Minas Gerais. Rev. Bras. Bot. 27:311-323.

SANDWITH, N.Y. \& HUNT, D.R. 1974. Bignoniaceas. Itajaí. Flora Ilustrada Catarinense, pt. 1.

SHANKAR, U. 2006. Seed size as a predictor of germination success and early seedling growth in "hollong" (Dipterocarpus macrocarpus Vesque). New Forest. 31:305-320. http://dx.doi.org/10.1007/s11056-005-8198-6

SOCOLOWSKI, F. 2007. Ecologia germinativa, relações alométricas e o efeito da massa das sementes de Tecoma stans L. Juss. ex Kunth (Bignoniaceae) sobre a emergência e desenvolvimento das plântulas. Tese de doutorado, Universidade Estadual Paulista, Rio Claro.
SPACE, J.C. \& IMADA, C.T. 2004. Report to the Republic of Kiribati on invasive plant species on the islands of Tarawa, Abemama, Butaritari and Maiana. U.S.D.A. Forest Service/Bishop Museum, Honolulu. http:// www.bishopmuseum.org/research/pbs/pdf/kiribati.pdf (último acesso em 22/08/2007).

STAMP, N.E. 1990. Production and effect of seed size in a grassland annual (Erodium brachycarpum, Geraniaceae). Am. J. Bot. 77:874-882. http:// dx.doi.org/10.2307/2444503

SUSKO, D.J. \& LOVETT-DOUST, L. 2000. Patterns of seed mass variation and their effects on seedling traits in Alliaria petiolata (Brassicaceae). Am. J. Bot. 87:56-66. PMid:10636830. http://dx.doi.org/10.2307/2656685

VIEIRA, D.C.M. 2009. Ecofisiologia de Clausena excavata Burm.f. (Rutaceae), uma espécie exótica invasora. Tese de doutorado, Universidade Estadual Paulista, Rio Claro.

WESTOBY, M., JURADO, E. \& LEISHMAN, M. 1992. Comparative evolutionary ecology of seed size. Trends Ecol. Evol. 7:368-372. http:// dx.doi.org/10.1016/0169-5347(92)90006-W

WRIGHT, I.J. \& WESTOBY, M. 2001. Understanding seedling growth relationships through specific leaf area and leaf nitrogen concentration: generalizations across growth forms and growth irradiance. Oecologia. 127:21-29. http://dx.doi.org/10.1007/s004420000554

WRIGHT, I.J., WESTOBY, M. \& REICH, P.B. 2002. Convergence towards higher leaf mass per unit area in dry and nutrient poor habitats has different consequences for life span. J. Ecol. 90:534-543. http://dx.doi. org/10.1046/j.1365-2745.2002.00689.x

ZAR, J.H. 1999. Biostatiscal analysis. Prentice Hall, New Jersey, 929p.

ZILLER, S.R. 2001. Plantas exóticas invasoras: a ameaça da contaminação biológica. Cienc. Hoje. 30:77-79.

ZIMMERMAN, J.K. \& WEIS, I.M. 1983. Fruit size variation and its effects on germination and seedling growth in Xanthium strumarium. Can. J. Botany. 60:2309-2315. http://dx.doi.org/10.1139/b83-253

Recebido em 28/02/2010

Versão reformulada recebida em 12/01/2011

Publicado em 15/06/2011 